\title{
Quizartinib Dihydrochloride
}

National Cancer Institute

\section{Source}

National Cancer Institute. Quizartinib Dihydrochloride. NCI Thesaurus. Code C97272.

The dihydrochloride salt form of quizartinib, an orally available small molecule with potential antineoplastic activity. Quizartinib selectively inhibits class III receptor tyrosine kinases, including FMS-related tyrosine kinase 3 (FLT3/ST K1), colony-stimulating factor 1 receptor (CSF1R/FMS), stem cell factor receptor (SCFR/KIT), and platelet derived growth factor receptors (PDGFRs), resulting in inhibition of ligand-independent leukemic cell proliferation and apoptosis. Mutations in FLT3, resulting in constitutive activation, are the most frequent genetic alterations in acute myeloid leukemia (AML) and occur in approximately one-third of AML cases. 